\title{
Identification of a novel functional JAK1 S646P mutation in acute Iymphoblastic leukemia
}

\author{
Qian $\mathrm{Li}^{1,2, *}$, Botao $\mathrm{Li}^{1,2, *}$, Liangding $\mathrm{Hu}^{1}$, Hongmei Ning ${ }^{1}$, Min Jiang ${ }^{1}$, Danhong \\ Wang ${ }^{1,2}$, Tingting Liu ${ }^{1}$, Bin Zhang ${ }^{1,2}$, Hu Chen ${ }^{1,2}$ \\ ${ }^{1}$ Department of Hematopoietic Stem Cell Transplantation, Affiliated Hospital of the Academy of Military Medical Sciences, \\ Beijing, China \\ ${ }^{2}$ Cell and Gene Therapy Center, Affiliated Hospital of the Academy of Military Medical Sciences, Beijing, China \\ *These authors contributed equally to this work
}

Correspondence to: Hu Chen, email: chenhu217@aliyun.com

Bin Zhang, email: zb307ctc@163.com

Keywords: acute lymphoblastic leukemia, whole-exome sequencing, mutation, JAK1, ruxolitinib

Received: July 10, $2016 \quad$ Accepted: March 17, $2017 \quad$ Published: March 29, 2017

Copyright: Li et al. This is an open-access article distributed under the terms of the Creative Commons Attribution License (CC-BY), which permits unrestricted use, distribution, and reproduction in any medium, provided the original author and source are credited.

\section{ABSTRACT}

The survival rate of childhood acute lymphoblastic leukemia (ALL) is approaching $\mathbf{9 0 \%}$, while the prognosis of adults remains poor due to the limited therapeutic approaches. In order to identify new targets for ALL, we performed whole-exome sequencing on four adults with B-ALL and discovered a somatic JAK1 S646P mutation. Sanger sequencing of JAK1 was conducted on 53 ALL patients, and two cases exhibited A639G and P960S mutations separately. Functional studies demonstrated that only JAK1 S646P mutation could activate multiple signaling pathways, drive cytokineindependent cell growth, and promote proliferation of malignant cells in nude mice. Moreover, a high sensitivity to the JAK1/2 inhibitor ruxolitinib was observed in S646P mutant model. Exploration in a total of 209 ALL cases showed that JAK1 mutations occur at a frequency of $10.5 \%$ in T-ALL $(2 / 19)$ and $1.6 \%$ in B-ALL $(3 / 190)$. Collectively, our results suggested that JAK1 S646P is an activating mutation in vitro and in vivo. JAK-STAT pathway might represent a promising therapeutic target for ALL.

\section{INTRODUCTION}

Acute lymphoblastic leukemia (ALL) is a malignant clonal disorder caused by the uncontrolled proliferation of immature lymphoblastic cells in bone marrow, which originate from the abnormal development of hematopoietic stem cells or lymphoid progenitor cells, and may be of B- or T- lymphoid lineage (B-ALL or T-ALL) [1]. ALL is seen in both children and adults, but with a peak at the age of 2-5 years [2]. Given the considerable progress in risk stratification and chemotherapy, the long-term survival rate of childhood ALL has improved to approximately $90 \%$ [3]. Although the overall survival of adult ALL improved to 30-40\% after adaptation of pediatric protocols, the prognosis remains poor due to the unsatisfactory response to chemotherapy [4].

Genetic alterations are vital events in leukemogenesis, and are closely related to the overall prognosis and relapse risk. Majority of ALL cases exhibit recurrent genetic alterations that are detectable by karyotyping, FISH or molecular techniques [5]. Current risk-stratification is mostly based on the presence and types of genetic abnormalities. BCR-ABL1 is the most common molecular abnormality in adult ALL and associated with poor outcome; by contrast, hyperdiplody and ETV6-RUNX1/TEL-AML1 (both associated with favorable outcome) are more common in childhood ALL, which may be partly responsible for the better outcome in children than that in adults [6]. However, current therapies that target specific genetic alterations remain insufficient, except for tyrosine kinase inhibitors (TKIs) such as imatinib in the treatment for BCR-ABL1-positive leukemia [7]. Therefore, the discovery of novel biological targets and agents is of great interest.

In order to identify novel mutations and therapeutic targets in ALL, we conducted whole-exome sequencing (WES) on four adult B-ALL patients without any known cytogenetic and molecular abnormality at diagnosis. In the course of screening, we identified and successfully validated a somatic JAK1 S646P mutation. Sanger 
sequencing of $J A K 1$ gene on additional 53 ALL cases discovered A639G and P960S mutations. Among them, only $\mathrm{S} 646 \mathrm{P}$ mutation was proved to be an activating mutation in vitro and in vivo. Moreover, the S646P mutant model exhibited an increased sensitivity to ruxolitinib, suggesting that it may act as a potential therapeutic target. The prevalence and clinical relevance of $J A K 1$ mutations were investigated in a total of 209 ALL cases, showed that $J A K 1$ mutations occur at a frequency of approximately $10.5 \%$ in T-ALL and $1.6 \%$ in B-ALL.

\section{RESULTS}

\section{Identification and validation of $J A K 1$ mutations in patients with $A \mathbf{L}$}

WES was successfully performed on newly diagnosed (blasts $>80 \%$ ) and paired remission (blasts $<5 \%$ ) bone marrow samples from four adults with B-ALL, who were not diagnosed with any known cytogenetic and molecular abnormality through routine laboratory examinations. The clinical characteristics of the four patients were listed in Table 1. To ensure the reliability and accuracy of the sequencing data, the average coverage of each base in the targeted regions was 50 -fold; $80 \%$ of the bases were represented at least 10 times. A total of 317 non-synonymous mutations and 27 nonsense mutations were identified in 337 genes (listed in Supplementary Table 2). 29 non-synonymous mutations in 24 genes were further validated by Sanger sequencing (listed in Supplementary Table 1). Somatic heterozygous JAK1 S646P mutation (located at exon 14), DOT1L F131L and E134K mutations (located at exon 5) were successfully validated. We then sequenced $J A K 1$ exon 14 and DOT1L exon 5 in additional 53 newly diagnosed ALL patients (B-ALL, $n=46$; T-ALL, $n=7$ ) using Sanger sequencing. No additional DOT1L mutation was identified, but a novel $J A K 1$ A639G mutation was found in one sample. Subsequently, all 25 exons of $J A K 1$ were analyzed in these 53 cases using Sanger sequencing, and the P960S mutation was identified in another sample. Together, all of the three identified $J A K 1$ mutations were heterozygous (Figure 1A). Among them, S646P and A639G mutations are newly discovered, and located at exon 14 in the pseudokinase domain, while P960S mutation (COSM4990582), which is located at exon 21 in the kinase domain, has been described in cutaneous squamous cell carcinoma [8] (Figure 1B).

Alignment of $J A K 1$ gene sequences from different species revealed that the mutant residues are highly conserved throughout vertebrate evolution (Figure 1C). These data demonstrated that the identified mutations are likely to play important roles in the structure and function of JAK1 protein.

\section{JAK1 S646P mutation induces constitutive activation of JAK-STAT and MAPK-ERK signaling pathways}

Given that HEK293V lack some endogenous cytokine receptors, such as IL-2R, IL-9R $\alpha$ and common $\gamma$ chain [9], cells that express gain-of-function mutations could induce constitutive activation of signaling pathways independent of cytokines and receptors, such as JAK2 V617F and its homologous mutant of JAK1 V658F [10]. To examine the effects of the identified mutations on signaling pathways, wild type (WT) or a mutant of JAK1 (A639G, S646P and P960S) was introduced transiently into HEK293V cells, autophosphorylation of JAK1 and phosphorylation of STAT3, ERK1/2 and AKT were compared basally, and $J A K 1 \mathrm{~V} 658 \mathrm{~F}$ mutation was used as a positive control. The data showed that expression of S646P and P960S mutations resulted in autophosphorylation of JAK1 (Figure 2A), and increased constitutive activation of STAT3 and ERK proteins, consistent with the positive control of V658F mutant. While WT and A639G groups exhibited no autophosphorylation of JAK1 and weak phosphorylation of STAT3 and ERK proteins (Figure 2B). No obvious difference was observed in AKT pathway among all groups. These data indicate that JAK1 S646P mutation can constitutively activate JAK1-STAT3 and MAPK-ERK pathways.

\section{JAK1 S646P mutation drives cytokine- independent growth of BaF3 cells}

To explore the transforming capability of the identified mutations, we used a cytokine independent growth assay with the murine pro B-cell BaF3 cell line. BaF3 cells normally depend on IL-3 for growth, but can grow in the absence of IL-3 when expressing with an oncogene, such as BCR-ABL1 fusion gene [11] and JAK2 V617F mutation [12]. We transduced BaF3 cells using lentiviral vector expressing WT or mutants of $J A K 1$ and selected for GFP-positive cells using puromycin $(1 \mu \mathrm{g} / \mathrm{ml})$. After withdrawing IL-3 for 3 days, BaF3 cells with S646P and V658F mutations could still grow, while other groups almost had no growth (Figure 3A).Meanwhile, we also observed that BaF3 cells with S646P and V658F mutations were resistant to IL-3 withdrawal-induced apoptosis, but cells with vector, WT or other mutants (A639G and P960S) underwent death in different degrees (Figure 3B). Cell survival curves also showed that only S646P and V658F mutations conferred the IL-3-independent growth of BaF3 cells (Figure 3C). Moreover, although BaF3 cells with S646P and V658F mutations were cultured without IL-3 in following experiments, they demonstrated an elevated percentage of $\mathrm{S} /$ G2 phase compared with other groups maintained with IL-3 (Figure 3D). These data suggest that both of JAK1 S646P and V658F mutations are gain-of-function. 
Table 1: Clinical characteristics of the four patients analyzed by WES

\begin{tabular}{ccccccc}
\hline Patient & Gender & Age & Lineage & Blasts (\%) (diagnosis/remission) & Cytogenetic abnormalities & Fusion Gene \\
\hline 1 & M & 22 & B-ALL & $81.0 / 5.0$ & - \\
2 & M & 15 & B-ALL & $95.5 / 3.0$ & - & - \\
3 & M & 22 & B-ALL & $92.0 / 2.5$ & - & - \\
4 & F & 40 & B-ALL & $96.2 / 2.5$ & - \\
\hline
\end{tabular}

Abbreviations: WES, whole-exome sequencing; ALL, acute lymphoblastic leukemia; M, male; F, female.

We also studied the effects of $J A K 1$ mutations on human B-ALL NALM-6 cell line, and observed that NALM-6 cells transduced with S646P mutation had an increased percentage of $\mathrm{S} / \mathrm{G} 2$ phase relative to other groups (Supplementary Figure 1), further confirming the promoting effect on cancer cell proliferation of JAKl S646P mutation.

\section{JAK1 S646P mutation leads to malignant proliferation of BaF3 cells in nude mice}

To explore the oncogenic potential of $\mathrm{BaF} 3$ cells with $J A K 1$ S646P mutation in vivo, we examined whether the intravenous inoculation of transduced $\mathrm{BaF} 3$ cells into nude mice could induce malignant proliferation.
$2 \times 10^{6} \mathrm{BaF} 3$ cells transduced with vector, WT $J A K 1$, or S646P mutation were intravenously inoculated (tail vein) into nude mice. During the weekly monitoring of peripheral blood, the $\mathrm{BaF} 3 / \mathrm{S} 646 \mathrm{P}$ mice exhibited statistically significant elevated white blood cells (WBC) counts (Figure 4A) and GFP-positive cells infiltration (Figure 4B) after 30 days post-inoculation. At the time of death, the inoculation of $\mathrm{BaF} 3 / \mathrm{S} 646 \mathrm{P}$ cells induced enlargement of liver and spleen relative to vector and WT controls (Figure 4C). The average weight of liver in $\mathrm{BaF} 3 /$ S646P cell-inoculated mice increased by about 1.2 to 1.4 fold $(1.46 \pm 0.25$ versus $1.19 \pm 0.1 \mathrm{~g}$ for $\mathrm{BaF} 3 / \mathrm{WT}$ and $1.02 \pm 0.09 \mathrm{~g}$ for BaF3/vector, $P<0.05$ ) (Figure 4D), and the average weight of spleen in $\mathrm{BaF} 3 / \mathrm{S} 646 \mathrm{P}$ mice increased by about 2 to 3 fold $(0.54 \pm 0.13$ versus $0.24 \pm 0.02 \mathrm{~g}$ for

A
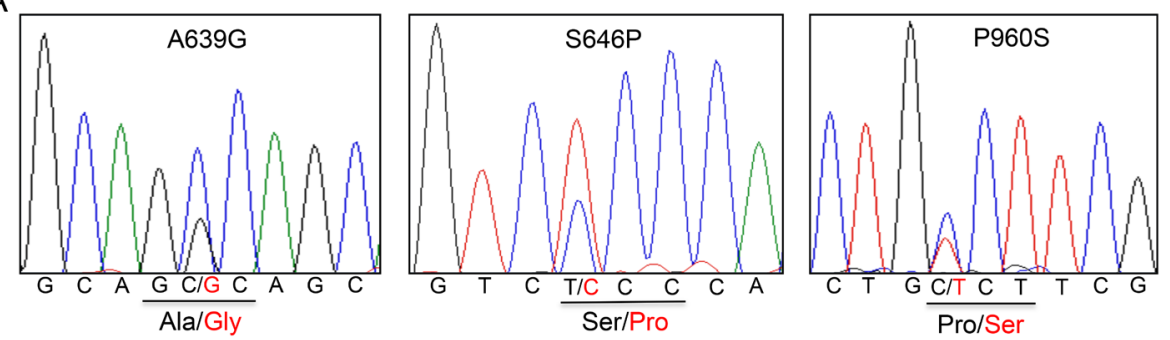

B

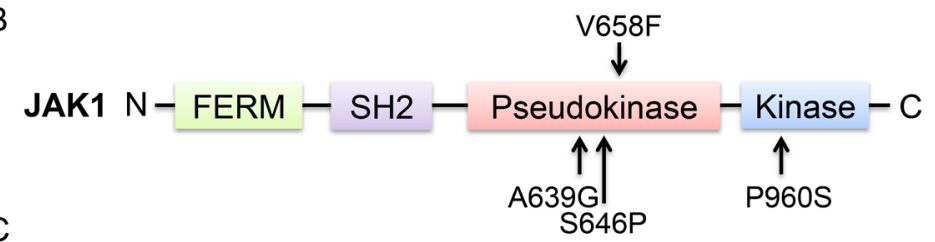

\begin{tabular}{|c|c|c|}
\hline Human & LKVLDPSHRDISLAFFEAASMMRQVSHKHIV & LIMEFLPSGSLK \\
\hline Chimpanzee & LKVLDPSHRDISLAFFEAASMMRQVSHKHIV & LIMEFLPSGSLK \\
\hline Monkey & LKVLDPSHRDISLAFFEAASMMRQVSHKHIV & LIMEFLPSGSLK \\
\hline Cow & LKVLDPSHRDISLAFFEAASMMRQVSHKHIV & LIMEFLPSGSLK \\
\hline Dog & LKVLDPSHRDISLAFFEAASMMRQVSHKHIV & LIMEFLPSGSLK \\
\hline Chicken & LKVLDPSHRDISLAFFEAASMMRQVSHKHIV & LIMEFLPSGSI \\
\hline Mouse & LKVLDPSHRDISLAFFEAASMMRQVSHKHIV & LIMEFLPSGS \\
\hline Rat & 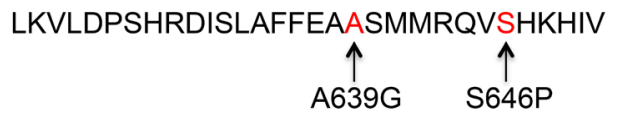 & $\underset{\uparrow}{\text { LIMEFLPS }}$ \\
\hline
\end{tabular}

Figure 1: Somatic non-synonymous mutations in conserved residues of JAK1. (A) Representative electropherograms of identified JAK1 mutations from 3 patients with ALL. Heterozygous mutations are indicated by double peaks. (B) Schematic diagram of JAK1 protein structure and location of affected residues. Somatic mutations are indicated by arrows. (C) Alignment of amino acid sequences of JAK1 residues. 

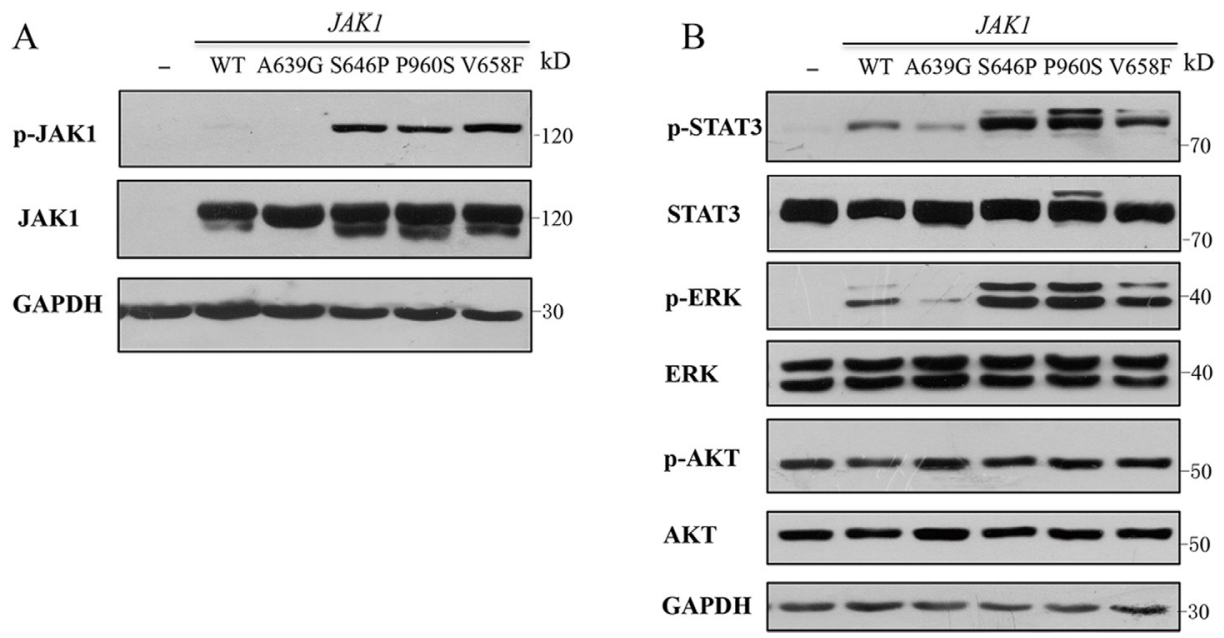

Figure 2: JAK1 S646P mutation induces constitutive activation of JAK-STAT and MAPK-ERK signaling pathways. (A) Autophosphorylation of JAK1 protein in HEK293V cells transiently transfected with wild-type (WT) or a mutant of JAK1 (A639G, S646P, P960S and V658F). (B) Phosphorylation of STAT3, ERK1/2 and AKT in HEK293V cells. Protein lysates of HEK293V cells transiently transfected with WT JAK1 or indicated mutants were analyzed by Western blot using specific antibodies shown. GAPDH was used as loading control. Similar results were obtained in 3 independent experiments.
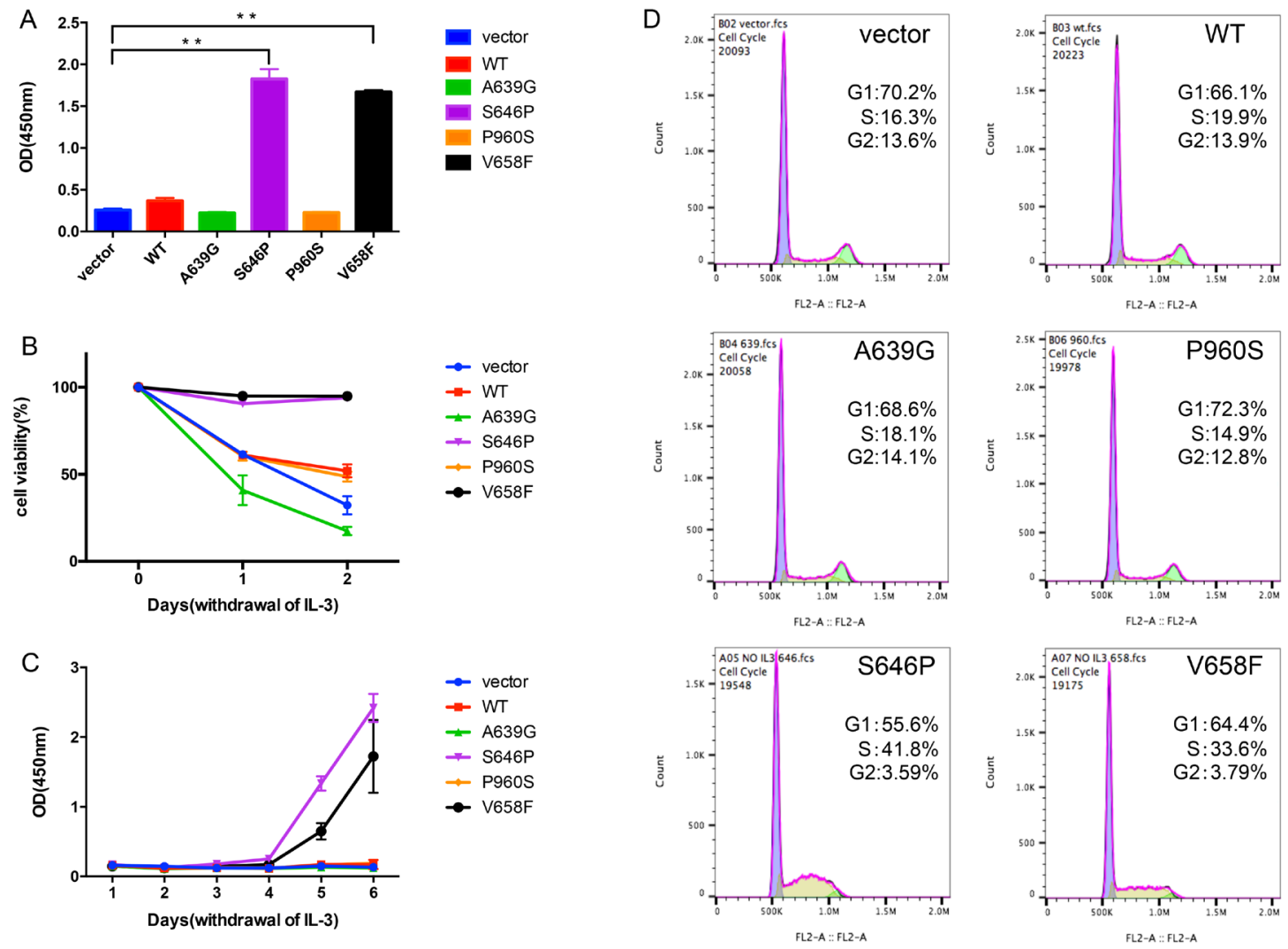

Figure 3: JAK1 S646P mutation drives IL-3-independent growth of BaF3 cells. (A) The proliferation of transduced BaF3 cells after withdrawing IL-3 for 3 days was assayed by CCK-8. Data are expressed as mean \pm s.d of at least 3 independent experiments. $* * P<0.01$. (B) The viability of transduced BaF3 cells after withdrawing IL-3 for $48 \mathrm{~h}$ was determined by trypan blue exclusion method at the indicated time points. (C) The survival curves of transduced BaF3 cells cultured in the absence of IL-3 for 6 days were determined by CCK-8. (D) Cell cycle histograms of transduced BaF3 cells were assayed by flow cytometry. The proportion of G1 or S/G2 phase is expressed as percentage of total cells. 
$\mathrm{BaF} 3 / \mathrm{WT}$ and $0.17 \pm 0.05 \mathrm{~g}$ for BaF3/vector, $P<0.05$ ) (Figure 4E). Histologic analysis of bone marrow smears revealed increased abnormal cells in $\mathrm{BaF} 3 / \mathrm{S} 646 \mathrm{P}$ mice relative to control groups (Figure $4 \mathrm{~F}$ ). The percentage of GFP-positive cells in bone marrow of BaF3/S646P mice was also higher than that in vector and WT control groups (Figure 4G). Therefore, we consider that the over expression of JAK1 S646P mutation could promote malignant proliferation of $\mathrm{BaF} 3$ cells in nude mice.

\section{JAK1 S646P mutation exhibits increased sensitivity to JAK1/2 inhibitor}

To detect the sensitivity of $J A K 1$ mutations to inhibitor, we examined whether ruxolitinib as an inhibitor for JAK1/2 could inhibit the activation of $J A K 1$ mutants. As shown in Figure 5A, treatment with increasing concentrations of ruxolitinib inhibited the autophosphorylation of JAK1 and constitutive activation of STAT3 and ERK1/2.

B
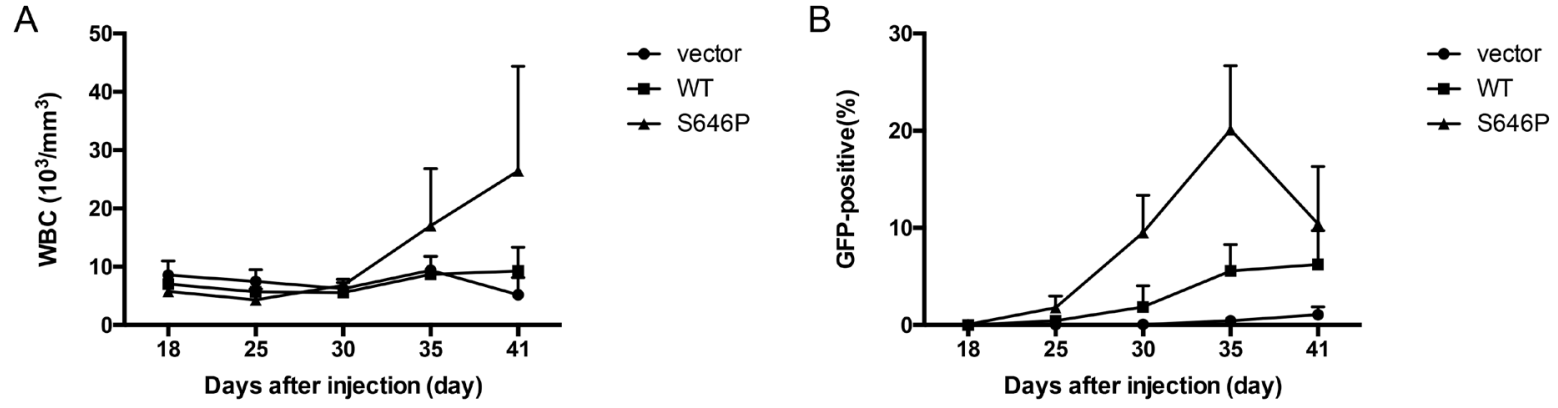

C

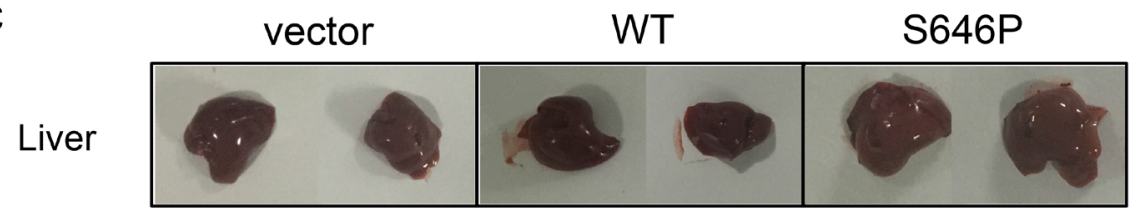

Spleen

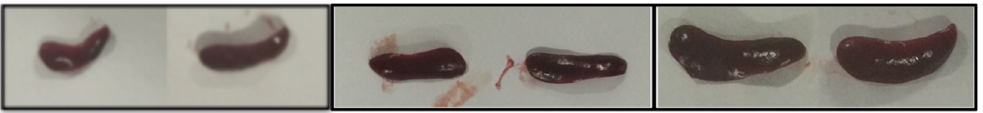

$\mathrm{D}$

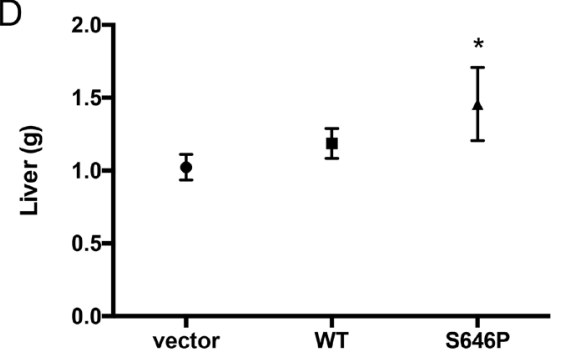

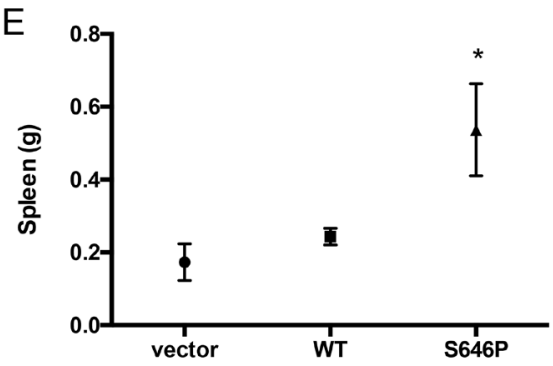

$\mathrm{F}$

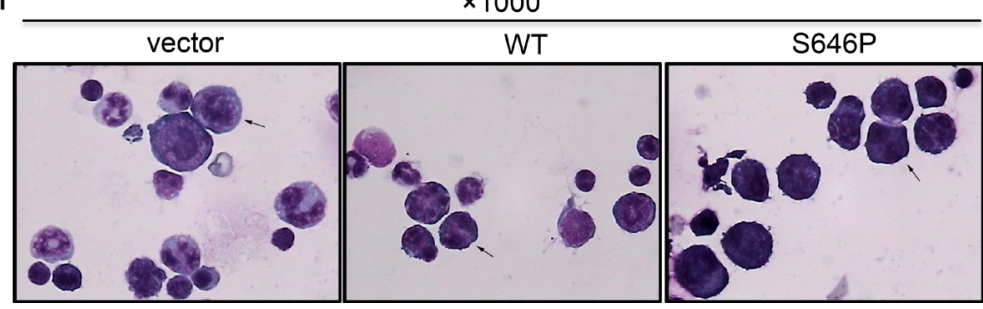

G

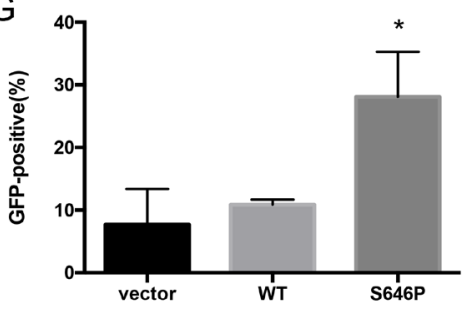

Figure 4: JAK1 S646P mutation induces malignant proliferation of BaF3 cells in nude mice. $2 \times 10^{6} \mathrm{BaF} 3$ cells transduced with vector, WT $J A K 1$, or S646P mutant were intravenously inoculated into nude mice. (A) WBC counts were monitored at the indicated time points. (B) GFP-positive cells in peripheral blood were monitored by flow cytometry. (C) At the time of sacrifice, the morphological changes of livers and spleens were photographed. (D, E) The weights of livers (D) and spleens (E) were recorded. Data are expressed as the mean \pm s.d. $* P<0.05$. (F) The bone marrow smears were stained with Wright and photographed (magnification: $\times 1000$ ). Representative abnormal cells were marked with arrows. (G) The percentage of GFP-positive cells in bone marrow at the time of sacrificed was detected by flow cytometry. Data are expressed as the mean \pm s.d. $* P<0.05$. 
Furthermore, we treated transduced BaF3 cells with increasing concentrations of ruxolitinib or solvent (DMSO) and assayed their proliferation. Except for autonomous BaF3 cells with S646P or V658F mutation, the rest of groups were cultured with IL-3. Chronic myeloid leukemia cell line K562 with BCR-ABL1 fusion gene was employed as a negative control due to its lack of sensitivity to JAK inhibitors [13]. Figure 5B showed that all transduced BaF3 cells were inhibited by high concentrations of ruxolitinib ( $>0.1 \mu \mathrm{m})$, while BaF3 cells with S646P and V658F mutations presented increased sensitivity to ruxolitinib, as at the concentration of $0.1 \mu \mathrm{m}$, their cell proliferation have been significantly inhibited relative to other groups.

\section{Prevalence and clinical relevance of $J A K 1$ mutations}

Since the identified $J A K 1$ mutations were focused in exon 14 and 21, we sequenced the two exons in additional 152 ALL patients (B-ALL, $n=140$; T-ALL, $n=12$ ) to determine the prevalence of $J A K 1$ mutations. Two patients with B-ALL were discovered with Y652H and N973K mutations separately. $\mathrm{Y} 652 \mathrm{H}$ has been described to be gain-of-function in T-ALL [14, 15], and N973K could be searched in dbSNP (rs34680086). Together, a cohort of 209 ALL patients were investigated, which is not restricted to a particular genetic subgroup (listed in Supplementary Table 3), and the prevalence of $J A K 1$ mutations were found at a frequency of approximately $2.4 \%$ in ALL $(5 / 209)$, especially more common in T-ALL $(2 / 19)$ than in B-ALL (3/190) (10.5\% versus $1.6 \%, P<0.05)$ (Table 2$)$.

The characteristics of patients with $J A K 1$ mutations were investigated and listed in Table 3. We observed that four mutation-positive patients ever relapsed and resisted to chemotherapy. Patient 1 with S646P mutation relapsed twice, and even presented the same mutation in relapsed blasts, indicating that this mutation may be associated with his relapse. Patient 3 with P960S mutation relapsed early after induction therapy, and resisted to multiple chemotherapies, even developed extramedullary

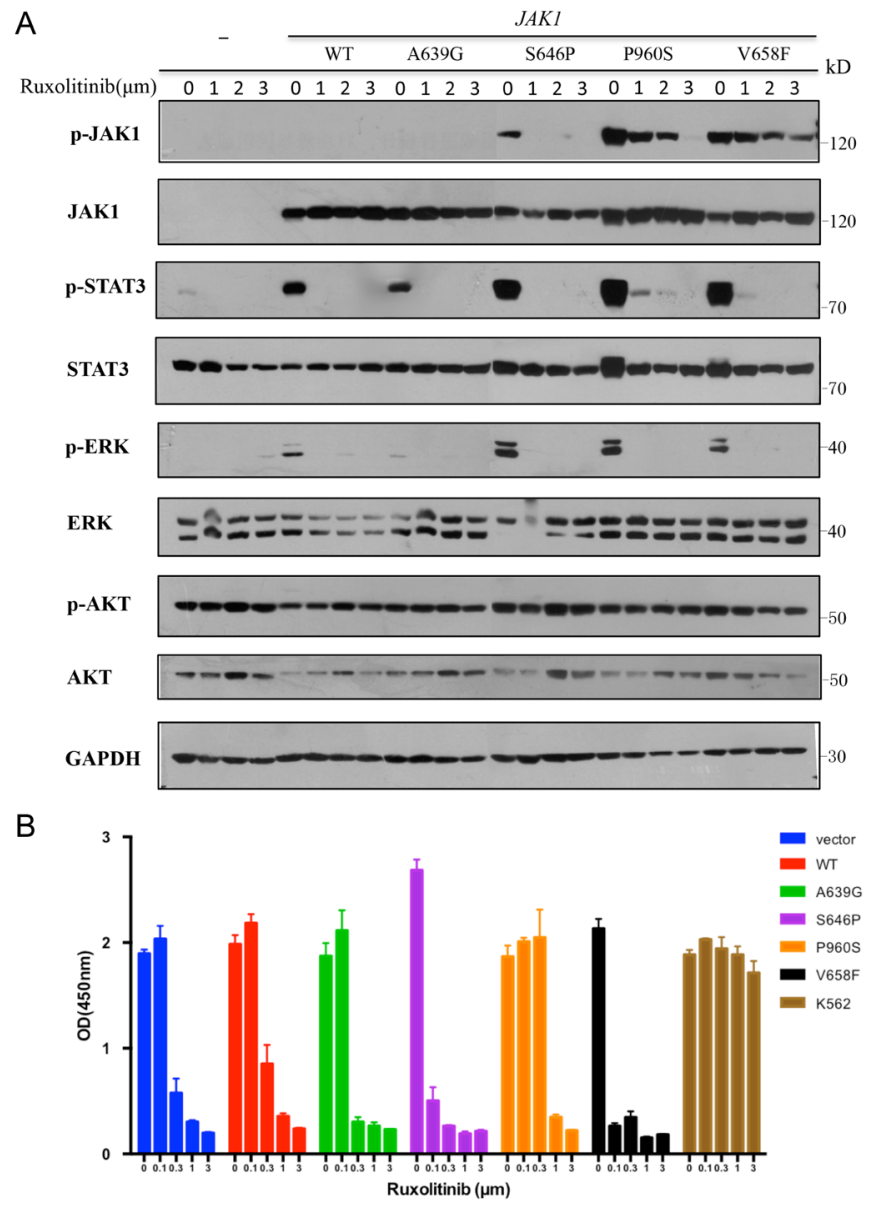

Figure 5: JAK1 S646P mutation exhibits increased sensitivity to JAK1/2 inhibitor. (A) Transiently transfected HEK293V cells were treated with increasing concentrations of ruxolitinib for $24 \mathrm{~h}$. Cell lysates were immunoblotted with specific antibodies shown. GAPDH was used as loading control. (B) Transduced BaF3 cells were treated with increasing concentrations of ruxolitinib for $48 \mathrm{~h}$. Cell proliferation was determined by CCK-8; K562 cells were used as negative control. Results represent the mean \pm s.d. of 3 independent experiments. 
Table 2: The occurrence of $J A K 1$ mutations in different subtypes of ALL

\begin{tabular}{cccc}
\hline \multirow{2}{*}{ Subtypes } & \multicolumn{3}{c}{ Events/Patients (Frequency) } \\
\cline { 2 - 4 } & Adults & Children & Total \\
\hline B-ALL & $2 / 109(1.8 \%)$ & $1 / 81(1.2 \%)$ & $3 / 190(1.6 \%)^{*}$ \\
T-ALL & $2 / 19(10.5 \%)$ & 0 & $2 / 19(10.5 \%)^{*}$ \\
Total & $4 / 128(3.1 \%)^{\#}$ & $1 / 81(1.2 \%)^{\#}$ & $5 / 209(2.4 \%)$ \\
\hline
\end{tabular}

Notes: The comparisons of occurrence of $J A K 1$ mutations in B-ALL and T-ALL or adults and children were performed using chi-square test, and $p$ values $<0.05$ were considered statistically significant. ${ }^{*} P<0.05 ;{ }^{\sharp} P>0.05$.

\section{Table 3: Characteristics of ALL patients with JAK1 mutations}

\begin{tabular}{ccccccccc}
\hline P & G & Age & Lineage & WBC $\left(\times \mathbf{1 0}^{\mathbf{9}} / \mathbf{L}\right)$ & Fusion Gene & Complex karyotype & AA substitution & Relapse \\
\hline 1 & M & 15 & B-ALL & 18.55 & - & - & Ser646Pro & + \\
2 & M & 32 & T-ALL & 25.2 & - & - & Ala639Gly & - \\
3 & M & 42 & T-ALL & 320.29 & - & - & Pro960Ser & + \\
4 & M & 17 & B-ALL & 11 & - & + & Tyr652His & + \\
5 & M & 3 & B-ALL & 45.95 & TCF3-PBX1 & + & Asn973Lys & + \\
\hline
\end{tabular}

Abbreviations: ALL, acute lymphoblastic leukemia; P, patient; G, gender; WBC, white blood cell; AA, amino acid; M, male.

infiltration in right eye. Patient 4 with $\mathrm{Y} 652 \mathrm{H}$ mutation harbored a complex karyotype (48, XY, +5, del (14) $(q 24),+19)$ at diagnosis. He relapsed extramedullarily at 3 years post-HSCT, diagnosed as B-cell lymphoblastic lymphoma encroached on double orbits and nasal cavity. N973K mutation was identified in a 3-year-old child (patient 5), who had a complex karyotype and the TCF3PBX1 fusion gene known to be associated with a high relapse risk [16]. He also relapsed early after a standard induction therapy. These data indicated that JAK1 S646P mutation might be associated with the patient's relapse, especially in the absence of other adverse prognostic factors. In addition, $J A K 1$ mutations may cooperate with other genetic aberrations to contribute to the dismal clinical course.

\section{DISCUSSION}

In the present study, we characterized a novel functional JAK1 S646P mutation in ALL identified by WES, which was able to activate JAK-STAT and MAPKERK signaling pathways, and drive IL-3-independent growth of $\mathrm{BaF} 3$ cells. In vivo, the inoculation of $\mathrm{BaF} 3$ cells with JAK1 S646P mutation induced malignant proliferation in nude mice. These data support that JAK1 S646P mutation is an activating mutation in ALL. In addition, other genes known to be affected by somatic mutations in hematologic cancers were also found from the WES data (Supplementary Table 3), such as JAK3, CREBBP, BCOR, and so on. JAK3 mutations were initially identified in patients with acute megakaryocytic leukemia [17], and mainly found in T-ALL and NKT lymphoma $[18,19]$. The deletion and sequence mutations of CREBBP, which encodes the transcriptional coactivator and histone acetyltransferase (HAT) CREB-binding protein (CBP), have been reported in $18.3 \%$ of ALL relapse cases, and the mutations may confer resistance to therapy [20, 21]. Besides, CREEB mutations also have been reported in $39 \%$ of DLBCL and $41 \%$ of follicular lymphoma (FL) patients [22]. BCOR, which possesses transcriptional activity, has been reported to be mutated in $4 \%$ of T-ALL [23] and $4.2 \%$ of MDS [24], and also associated with the disease progression.

JAK genes encode non-receptor tyrosine kinases, including 4 members, JAK1, JAK2, JAK3, and TYK2 [25]. A point mutation of JAK2 V617F was found in more than $50 \%$ of patients with myeloproliferative neoplasms (MPNs) [26]. This mutation has shown to be gain-of-function in vitro and in vivo [27]. Previous studies demonstrated that $J A K 1 \mathrm{~V} 658 \mathrm{~F}$ mutation is homologous to $J A K 2 \mathrm{~V} 617 \mathrm{~F}$, and able to constitutively activate JAK1-STAT3 pathway [10, 28, 29]. Both of V658F and $\mathrm{S} 646 \mathrm{P}$ mutations are located in the pseudokinase domain of JAK1, and exhibit a similar function in the present study, indicating that S646P mutation may cause the constitutive activation of JAK1 kinase via disrupting the auto-inhibition as V658F. Similarly, JAK1 A634D and $\mathrm{R} 724 \mathrm{H}$ mutations described in T-ALL [30], and V623A mutation in AML [31], were also located in the pseudokinase domain and exhibited activating function in vitro proliferation assays. In addition, similar to our results in nude mice, $\mathrm{BaF} 3$ cells transduced with $J A K 2$ L611S mutation, which was reported in a child with ALL [32], has also been proposed to be of oncogenic ability to induce tumorigenesis in nude mice and prompt invasion into various organs [33].

The pseudokinase domain of JAK1 protein is analogous to the kinase domain, and functions as a 
negative regulator of kinase activity [34]. The available data support the view that the recurrent activating mutations are mostly located at the pseudokinase domain of JAKs [14, 29, 30], the pathogenic mechanism is predicted to interfere with auto-inhibition on the catalytic activity [30]. However, we provide the first evidence that not all mutations at pseudokinase domain are gainof-function, such as JAK1 A639G mutation, which did not induce the cytokine-independent cell growth and activation of downstream signaling pathways. This finding indicated that the molecular modeling and location of affected residues should be fully characterized. It is proposed that structural rearrangements in the regions involved in interdomain interactions between the pseudokinase and kinase domains or the FERM and SH2 domains, particularly in G-Loop, which participates in active tyrosine kinases [31], are likely to be gain-offunction [35]. In addition, it seems that the mutations at kinase domain have no transforming capability, since P960S mutation cannot drive cytokine-independent cell growth, similar to R879C described in T-ALL [30]. However, both of them showed increased activation of signaling pathways, suggesting that the cell transformation process is involved with other signals or molecules interacting with the pseudokinase domain.

Adverse prognostic factors in adult ALL consist of age $\left(>35\right.$ years), an elevated WBC count $\left(>30 \times 10^{9} / \mathrm{L}\right.$ in B-ALL and $>100 \times 10^{9} / \mathrm{L}$ in T-ALL), and complex karyotype. Flex et al. reported $J A K 1$ mutations occurred at a frequency of $4.6 \%$ in ALL, also more commonly in T-ALL than in B-ALL. They provided evidence that $J A K 1$ mutations in adult T-ALL are associated with a poor response to therapy, frequent relapse and reduced overall survival [30]. In our study, we observed that four mutation-positive patients ever relapsed and resisted to chemotherapy. However, based on the available data, we cannot confirm whether $J A K 1$ mutation is a poor prognosis factor for ALL with the relatively small size of the study cohort. Larger cohorts are required to estimate the clinical relevance of such mutations in ALL. Furthermore, the dysfunction of $J A K 1$ mainly results in impaired lymphopoiesis [36], consistent with previous studies [29, 30, 37], we revealed that $J A K 1$ mutations occur at a frequency of approximately $2.4 \%$ in ALL, and more commonly in T-ALL than in B-ALL. This result can be explained by the opinion that activation of JAK1 and NOTCH1 pathways might cooperate in T-ALL pathogenesis and progression $[23,30]$, encouraging the studies on combination of several targeted therapies in refractory/relapse cases..

A JAK1/2 inhibitor, ruxolitinib, has been approved by FDA for the treatment of patients with intermediate or high-risk myelofibrosis and polycythemia vera [38, 39]. Recently, it was also tested in clinical trials for the treatment of Ph-like ALL, which was identified by abnormalities in the Ras and JAK/STAT pathways.
We showed that all of $J A K 1$ mutations are sensitive to ruxolitinib, and $\mathrm{S} 646 \mathrm{P}$ mutation exhibits an increased sensitivity, indicating that ruxolitinib could be valuable for patients with $J A K 1$ abnormalities. Combined multiple targeting drugs may be of more clinical benefit for ALL.

In summary, our work provides the first evidence that the newly identified JAK1 S646P mutation is an activating mutation in vitro and in vivo, and highly sensitive to JAK inhibitor, encouraging studies aimed at testing the efficacy and side effects of ruxolitinib in the treatment for ALL. Moreover, studies on larger cohorts are required to estimate the clinical relevance and prognostic value of such mutations in ALL.

\section{MATERIALS AND METHODS}

\section{Human subjects}

The Institutional Review Board of the Affiliated Hospital of the Academy of Military Medical Sciences approved this study, and informed consent was obtained from all patients. Paired bone marrow DNA samples from 4 adult patients with B-ALL at diagnosis (more than $80 \%$ bone marrow involvement by leukemia) and in remission (less than 5\% involvement) were conducted for WES. These four patients were not detected with any known cytogenetic and molecular abnormality through chromosome G-banding karyotype analysis and RTPCR for lymphoid and myeloid related fusion genes or mutations at diagnosis, including MLL/AFX, MLL/AF6, MLL/AF1q, MLL/AF1p, MLL/AF10, MLL/AF9, MLL/ ENL, MLL/ELL, dupMLL, NPM/ALK, MLL/AF17, MLL/AF4, SIL/TAL1, E2A/Pbx1, TEL/AML1, E2A/ HLF, NPM/MLF1, AML1/MDS1/EVI1, TEL/ABL, TEL/ PDGFR, DEK/CAN, CBF $\beta / M Y H 11$, AML1/ETO, SET/ CAN, BCR/ABL1, TLS/ERG, NPM/RAR $\alpha$, PML/RAR $\alpha$, PLZF/RAR $\alpha$, HOX11, EVI1, FLT3-ITD, c-kit, NPM1, $\mathrm{C} / \mathrm{EBP} \alpha$ and JAK2. In addition, genomic DNA samples isolated from 205 patients with ALL (B-ALL, $n=186$; T-ALL, $n=19$ ) were sequenced for JAK1 using Sanger sequencing. Among them, 53 patients (B-ALL, $n=46$; T-ALL, $n=7$ ) were analyzed for all exons of $J A K 1$, and 152 patients (B-ALL, $n=140$; T-ALL, $n=12$ ) were analyzed for exons 14 and 21 of $J A K 1$.

\section{Exome sequencing and mutation analysis}

As previously reported, exome sequencing was performed on 4 adult patients with B-ALL [40, 41]. In brief, an exome capturing sequencing library was produced from Agilent's SureSelect Human All Exon V5, followed by sequencing on the Illumina HiSeqTM2000 platform. Candidate variants were confirmed by Sanger sequencing. Mutation analysis for $J A K 1$ in a large cohort was performed by PCR amplification of specific exons and Sanger sequencing. 


\section{Cell culture and cytokines}

$\mathrm{BaF} 3$ murine pro-B cells was obtained from the China Infrastructure of Cell Line Resources, cultured in RPMI 1640 medium (Hyclone, Logan, Utah, USA) with $10 \%$ fetal bovine serum (FBS) (Gibco, California, USA) and $10 \mathrm{ng} / \mathrm{ml} \mathrm{mIL-3} \mathrm{(Peprotech,} \mathrm{Rocky} \mathrm{Hill,} \mathrm{USA).}$ NALM-6 human B-ALL cells (Biopike, Beijing, China) were cultured in RPMI 1640 medium with $10 \%$ FBS. HEK293V cells (Inovogen, Beijing, China) were cultured in DMEM medium (Hyclone, Logan, Utah, USA) with $10 \% \mathrm{FBS}$.

\section{Plasmid constructs, virus production and transfection}

Human JAK1 cDNA was obtained from pDONR223_JAK1 (Addgene, Cambridge, MA, USA), and subcloned into the lentiviral expression vector pLV-EGFP(2A)Puro (Inovogen, Beijing, China). The mutations resulting in A639G, S646P, P960S, and V658F substitutions were introduced into JAK1 coding sequence by site-directed mutagenesis and confirmed by full-length DNA sequencing. Lentiviral supernatants were generated by co-transfection of lentiviral packaging plasmids and expression vector into HEK293V cells using $\mathrm{CaCl}_{2}$, harvested at $48 \mathrm{~h}$ and $72 \mathrm{~h}$ post-transfection. The supernatants were then concentrated and purified using Amicon $^{\circledR}$ Pro Purification System (Merck Millipore, Darmstadt, Germany). To estimate viral titers, HEK293V cells were incubated for $72 \mathrm{~h}$ with graded amounts of viral supernatant. $\mathrm{BaF} 3$ and NALM-6 cells were infected with the concentrated lentiviral supernatants $(\mathrm{MOI}=10)$ and $8 \mu \mathrm{g} / \mathrm{mL}$ polybrene (Sigma-Aldrich, St Louis, MO, USA). The expression of GFP was analyzed by Accuri C6 (BD Biosciences, San Jose, CA, USA). Transduced BaF3 and NALM-6 cells were selected in growth media containing $1 \mu \mathrm{g} / \mathrm{ml}$ puromycin (Sigma-Aldrich, St Louis, MO, USA) for 7 days.

\section{Cell proliferation and apoptosis assays}

Transduced $\mathrm{BaF} 3$ cells were washed three times with PBS, $1 \times 10^{5}$ cells/well were seeded in 96-well plates, cultured in RPMI 1640 medium supplemented with $10 \%$ FBS in the absence of IL-3. Three days later, cell proliferation was assessed using a Cell Counting Kit 8 (CCK-8, Dojindo,Tokyo, Japan) assay as previously described [42]. The cell growth curves of transduced $\mathrm{BaF} 3$ were also determined using this assay. In brief, 2000 cells/ well were seeded in 96-well plates and cultured in the absence of IL-3.10 $\mu$ 1 CCK- 8 was added to the wells at the indicated time points for $2 \mathrm{~h}$, and the absorbance at 450 nm was measured by iMark (Bio-rad, Hercules, California, USA). Cell viability after withdrawal of IL-3 for $48 \mathrm{~h}$ was checked by trypan blue exclusion method.

\section{Cell cycle analysis}

$2 \times 10^{6}$ IL-3-dependent BaF3 cells or autonomous $\mathrm{BaF} 3$ cells were cultured in the presence or absence of mIL-3, respectively. Cells were washed twice with PBS and fixed with $70 \%(\mathrm{v} / \mathrm{v})$ ethanol at $4{ }^{\circ} \mathrm{C}$ overnight, then were washed twice and incubated in PBS that contains $100 \mu \mathrm{g} / \mathrm{ml}$ RNaseA and $50 \mu \mathrm{g} / \mathrm{ml}$ propidium iodide (Sigma-Aldrich, St Louis, MO, USA) for $30 \mathrm{~min}$. Cell cycle parameters were determined by Accuri C6 (BD Biosciences, San Jose, CA, USA). All data were recorded and analyzed using Flowjo software (Treestar, Version 10.1).

\section{Western blotting}

$1 \times 10^{6}$ HEK293V cells were transiently transfected with $5 \mu \mathrm{g}$ of empty vector (vector), wild-type (WT) or JAK1 mutant (A639G, S646P, P960S and V658F) plasmid using vigofect (Vigorous Biotechnology, Beijing, China). Cell lysate preparation, gel electrophoresis and transfer to polyvinylidene difluoride (PVDF) membranes were performed as previously described [33]. The phosphorylation of signaling proteins was investigated with the following phospho-specific antibodies: antiphospho-JAK1 (Tyr1022/1023), anti-phospho-ERK (Thr202/Tyr204) and anti-phospho-AKT (Ser473) antibodies were purchased from Cell Signaling Technology (CST, Danvers, MA, USA). Anti-phosphoSTAT3 (Tyr705) antibody was purchased from Abcam (Cambridge, UK). Blots were re-probed with antiJAK1 (Abcam, Cambridge, UK), anti-STAT3 (Abcam, Cambridge, UK), anti-ERK1/2 (CST, Danvers, MA, USA), anti-AKT (CST, Danvers, MA, USA), and antiGAPDH (Transgen biotech, Beijing, China) antibodies.

\section{Animal tumorigenesis in nude mice}

The Institutional Review Board of the Affiliated Hospital of the Academy of Military Medical Sciences approved all mouse experiments. To test the oncogenic ability of JAK1 S646P mutant in vivo, $2 \times 10^{6} \mathrm{BaF} 3$ cells transduced with vector, WT or JAK1 S646P mutant were injected intravenously into nude mice aged 5 to 6 weeks. Blood counts were monitored weekly after 15 days post-inoculation. After sacrificing the mice, their livers and spleens were photographed and weighed. The bone marrow smears were stained with Wright and analyzed for the blasts infiltration. Single-cell suspensions were prepared from peripheral blood and bone marrow, and were analyzed for the percentage of GFP-positive cells by flow cytometry.

\section{Statistics}

The experimental data are shown as the mean value with bars representing the standard deviation of the mean (s.d.). Data were analyzed using GraphPad Prism Version 6.0. Statistical significance was determined using student's 
$t$-test for comparison of two groups or ANOVA with multiple groups. The comparison of occurrence of $J A K 1$ mutations in B-ALL and T-ALL was performed using chisquare test. $P$ values $<0.05$ were considered statistically significant.

\section{ACKNOWLEDGMENTS}

We gratefully thank the Biological Sample Bank from the Affiliated Hospital of the Academy of Military Medical Sciences and the Department of Pediatric from Institute of Hematology and Blood Diseases Hospital for samples assistance.

\section{CONFLICTS OF INTEREST}

All authors claimed that there is no conflicts of interest.

\section{GRANT SUPPORT}

This work was supported by the National Hightech R\&D Program of China (863 Program)(grant numbers2011AA020114, 2013AA020103).

\section{REFERENCES}

1. Mullighan CG. New strategies in acute lymphoblastic leukemia: translating advances in genomics into clinical practice. Clin Cancer Res. 2011; 17:396-400.

2. Inaba $\mathrm{H}$, Greaves $\mathrm{M}$, Mullighan $\mathrm{CG}$. Acute lymphoblastic leukaemia. Lancet. 2013; 381:1943-1955.

3. Hunger SP, Lu X, Devidas M, Camitta BM, Gaynon PS, Winick NJ, Reaman GH, Carroll WL. Improved survival for children and adolescents with acute lymphoblastic leukemia between 1990 and 2005: a report from the children's oncology group. J Clin Oncol. 2012; 30:1663-1669.

4. Bassan R, Hoelzer D. Modern therapy of acute lymphoblastic leukemia. J Clin Oncol. 2011; 29:532-543.

5. Hicks C, Miele L, Koganti T, Young-Gaylor L, Rogers D, Vijayakumar V, Megason G. Analysis of Patterns of Gene Expression Variation within and between Ethnic Populations in Pediatric B-ALL. Cancer Inform. 2013; 12:155-173.

6. Downing JR, Wilson RK, Zhang J, Mardis ER, Pui CH, Ding L, Ley TJ, Evans WE. The Pediatric Cancer Genome Project. Nat Genet. 2012; 44:619-622.

7. Druker BJ, Sawyers CL, Kantarjian H, Resta DJ, Reese SF, Ford JM, Capdeville R, Talpaz M. Activity of a specific inhibitor of the BCR-ABL tyrosine kinase in the blast crisis of chronic myeloid leukemia and acute lymphoblastic leukemia with the Philadelphia chromosome. N Engl J Med. 2001; 344:1038-1042.

8. Li YY, Hanna GJ, Laga AC, Haddad RI, Lorch JH, Hammerman PS. Genomic analysis of metastatic cutaneous squamous cell carcinoma. Clin Cancer Res. 2015; 21:1447-1456.

9. Losdyck E, Hornakova T, Springuel L, Degryse S, Gielen O, Cools J, Constantinescu SN, Flex E, Tartaglia M, Renauld JC, Knoops L. Distinct Acute Lymphoblastic Leukemia (ALL)associated Janus Kinase 3 (JAK3) Mutants Exhibit Different Cytokine-Receptor Requirements and JAK Inhibitor Specificities. J Biol Chem. 2015; 290:29022-29034.

10. Hornakova T, Staerk J, Royer Y, Flex E, Tartaglia M, Constantinescu SN, Knoops L, Renauld JC. Acute lymphoblastic leukemia-associated JAK1 mutants activate the Janus kinase/STAT pathway via interleukin-9 receptor alpha homodimers. J Biol Chem. 2009; 284:6773-6781.

11. Parada Y, Banerji L, Glassford J, Lea NC, Collado M, Rivas C, Lewis JL, Gordon MY, Thomas NS, Lam EW. BCR-ABL and interleukin 3 promote haematopoietic cell proliferation and survival through modulation of cyclin D2 and p27Kip1 expression. J Biol Chem. 2001; 276:23572-23580.

12. James C, Ugo V, Le Couedic JP, Staerk J, Delhommeau F, Lacout C, Garcon L, Raslova H, Berger R, BennaceurGriscelli A, Villeval JL, Constantinescu SN, Casadevall N, et al. A unique clonal JAK2 mutation leading to constitutive signalling causes polycythaemia vera. Nature. 2005; 434:1144-1148.

13. Koo GC, Tan SY, Tang T, Poon SL, Allen GE, Tan L, Chong SC, Ong WS, Tay K, Tao M, Quek R, Loong S, Yeoh KW, et al. Janus kinase 3-activating mutations identified in natural killer/T-cell lymphoma. Cancer Discov. 2012; 2:591-597.

14. Kleppe M, Soulier J, Asnafi V, Mentens N, Hornakova T, Knoops L, Constantinescu S, Sigaux F, Meijerink JP, Vandenberghe P, Tartaglia M, Foa R, Macintyre E, et al. PTPN2 negatively regulates oncogenic JAK1 in T-cell acute lymphoblastic leukemia. Blood. 2011; 117:7090-7098.

15. Porcu M, Kleppe M, Gianfelici V, Geerdens E, De Keersmaecker K, Tartaglia M, Foa R, Soulier J, Cauwelier B, Uyttebroeck A, Macintyre E, Vandenberghe P, Asnafi V, et al. Mutation of the receptor tyrosine phosphatase PTPRC (CD45) in T-cell acute lymphoblastic leukemia. Blood. 2012; 119:4476-4479.

16. Mullighan CG. Genomic profiling of B-progenitor acute lymphoblastic leukemia. Best Pract Res Clin Haematol. 2011; 24:489-503.

17. Walters DK, Mercher T, Gu TL, O'Hare T, Tyner JW, Loriaux M, Goss VL, Lee KA, Eide CA, Wong MJ, Stoffregen EP, McGreevey L, Nardone J, et al. Activating alleles of JAK3 in acute megakaryoblastic leukemia. Cancer cell. 2006; 10:65-75.

18. Elliott NE, Cleveland SM, Grann V, Janik J, Waldmann TA, Dave UP. FERM domain mutations induce gain of function in JAK3 in adult T-cell leukemia/lymphoma. Blood. 2011; 118:3911-3921.

19. Bains T, Heinrich MC, Loriaux MM, Beadling C, Nelson D, Warrick A, Neff TL, Tyner JW, Dunlap J, Corless CL, Fan G. Newly described activating JAK3 mutations in T-cell acute 
lymphoblastic leukemia. Leukemia. 2012; 26:2144-2146.

20. Mullighan CG, Zhang J, Kasper LH, Lerach S, PayneTurner D, Phillips LA, Heatley SL, Holmfeldt L, CollinsUnderwood JR, Ma J, Buetow KH, Pui CH, Baker SD, et al. CREBBP mutations in relapsed acute lymphoblastic leukaemia. Nature. 2011; 471:235-239.

21. Inthal $A$, Zeitlhofer $P$, Zeginigg $M$, Morak $M$, Grausenburger R, Fronkova E, Fahrner B, Mann G, Haas OA, Panzer-Grumayer R. CREBBP HAT domain mutations prevail in relapse cases of high hyperdiploid childhood acute lymphoblastic leukemia. Leukemia. 2012; 26:1797-1803.

22. Pasqualucci L, Dominguez-Sola D, Chiarenza A, Fabbri G, Grunn A, Trifonov V, Kasper LH, Lerach S, Tang H, Ma J, Rossi D, Chadburn A, Murty VV, et al. Inactivating mutations of acetyltransferase genes in B-cell lymphoma. Nature. 2011; 471:189-195.

23. Neumann M, Vosberg S, Schlee C, Heesch S, Schwartz S, Gokbuget N, Hoelzer D, Graf A, Krebs S, Bartram I, Blum H, Bruggemann M, Hecht J, et al. Mutational spectrum of adult T-ALL. Oncotarget. 2015; 6:2754-2766. doi: 10.18632/oncotarget.2218.

24. Damm F, Chesnais V, Nagata Y, Yoshida K, Scourzic L, Okuno Y, Itzykson R, Sanada M, Shiraishi Y, GelsiBoyer V, Renneville A, Miyano S, Mori H, et al. BCOR and BCORL1 mutations in myelodysplastic syndromes and related disorders. Blood. 2013; 122:3169-3177.

25. Lee HJ, Daver N, Kantarjian HM, Verstovsek S, Ravandi F. The role of JAK pathway dysregulation in the pathogenesis and treatment of acute myeloid leukemia. Clin Cancer Res. 2013; 19:327-335.

26. Kralovics R, Passamonti F, Buser AS, Teo SS, Tiedt R, Passweg JR, Tichelli A, Cazzola M, Skoda RC. A gain-offunction mutation of JAK2 in myeloproliferative disorders. N Engl J Med. 2005; 352:1779-1790.

27. Akada H, Yan D, Zou H, Fiering S, Hutchison RE, Mohi MG. Conditional expression of heterozygous or homozygous JAK2V617F from its endogenous promoter induces a polycythemia vera-like disease. Blood. 2010; 115:3589-3597.

28. Mullighan CG, Collins-Underwood JR, Phillips LA, Loudin MG, Liu W, Zhang J, Ma J, Coustan-Smith E, Harvey RC, Willman CL, Mikhail FM, Meyer J, Carroll AJ, et al. Rearrangement of CRLF2 in B-progenitor- and Down syndrome-associated acute lymphoblastic leukemia. Nat Genet. 2009; 41:1243-1246.

29. Jeong EG, Kim MS, Nam HK, Min CK, Lee S, Chung YJ, Yoo NJ, Lee SH. Somatic mutations of JAK1 and JAK3 in acute leukemias and solid cancers. Clin Cancer Res. 2008; 14:3716-3721.

30. Flex E, Petrangeli V, Stella L, Chiaretti S, Hornakova T, Knoops L, Ariola C, Fodale V, Clappier E, Paoloni F, Martinelli S, Fragale A, Sanchez M, et al. Somatically acquired JAK1 mutations in adult acute lymphoblastic leukemia. J Exp Med. 2008; 205:751-758.

31. Xiang Z, Zhao Y, Mitaksov V, Fremont DH, Kasai Y, Molitoris A, Ries RE, Miner TL, McLellan MD,
DiPersio JF, Link DC, Payton JE, Graubert TA, et al. Identification of somatic JAK1 mutations in patients with acute myeloid leukemia. Blood. 2008; 111:4809-4812.

32. Kratz CP, Boll S, Kontny U, Schrappe M, Niemeyer CM, Stanulla M. Mutational screen reveals a novel JAK2 mutation, L611S, in a child with acute lymphoblastic leukemia. Leukemia. 2006; 20:381-383.

33. Funakoshi-Tago M, Tago K, Sumi K, Abe M, AizuYokota E, Oshio T, Sonoda Y, Kasahara T. The acute lymphoblastic leukemia-associated JAK2 L611S mutant induces tumorigenesis in nude mice. J Biol Chem. 2009; 284:12680-12690.

34. Gordon GM, Lambert QT, Daniel KG, Reuther GW. Transforming JAK1 mutations exhibit differential signalling, FERM domain requirements and growth responses to interferon-gamma. Biochem J. 2010; 432:255-265.

35. Toms AV, Deshpande A, McNally R, Jeong Y, Rogers JM, Kim CU, Gruner SM, Ficarro SB, Marto JA, Sattler M, Griffin JD, Eck MJ. Structure of a pseudokinase-domain switch that controls oncogenic activation of JAK kinases. Nat Struct Mol Biol. 2013; 20:1221-1223.

36. Chen E, Staudt LM, Green AR. Janus kinase deregulation in leukemia and lymphoma. Immunity. 2012; 36:529-541.

37. Zhang J, Mullighan CG, Harvey RC, Wu G, Chen X, Edmonson M, Buetow KH, Carroll WL, Chen IM, Devidas M, Gerhard DS, Loh ML, Reaman GH, et al. Key pathways are frequently mutated in high-risk childhood acute lymphoblastic leukemia: a report from the Children's Oncology Group. Blood. 2011; 118:3080-3087.

38. Raedler LA. Jakafi (Ruxolitinib): First FDA-Approved Medication for the Treatment of Patients with Polycythemia Vera. Am Health Drug Benefits. 2015; 8:75-79.

39. Eghtedar A, Verstovsek S, Estrov Z, Burger J, Cortes J, Bivins C, Faderl S, Ferrajoli A, Borthakur G, George S, Scherle PA, Newton RC, Kantarjian HM, et al. Phase 2 study of the JAK kinase inhibitor ruxolitinib in patients with refractory leukemias, including postmyeloproliferative neoplasm acute myeloid leukemia. Blood. 2012; 119:4614-4618.

40. Neumann M, Heesch S, Schlee C, Schwartz S, Gokbuget N, Hoelzer D, Konstandin NP, Ksienzyk B, Vosberg S, Graf A, Krebs S, Blum H, Raff T, et al. Whole-exome sequencing in adult ETP-ALL reveals a high rate of DNMT3A mutations. Blood. 2013; 121:4749-4752.

41. Greif PA, Yaghmaie M, Konstandin NP, Ksienzyk B, Alimoghaddam K, Ghavamzadeh A, Hauser A, Graf A, Krebs S, Blum H, Bohlander SK. Somatic mutations in acute promyelocytic leukemia (APL) identified by exome sequencing. Leukemia. 2011; 25:1519-1522.

42. Li C, Cai S, Wang X, Jiang Z. Identification and characterization of ANO9 in stage II and III colorectal carcinoma. Oncotarget. 2015; 6:29324-29334. doi: 10.18632/oncotarget.4979. 